\title{
Large-scale impact of digital library services: findings from a major evaluation of SCRAN
}

\author{
Gobinda Chowdhury, David McMenemy and Alan Poulter \\ Department of Computer and Information Sciences, University of Strathclyde, \\ Glasgow G1 1XH, UK \\ \{gobinda.chowdhury, david.mcmenemy, \\ alan.poulter, ecis.strath.ac.uk
}

\begin{abstract}
This paper reports on an evaluation carried out on behalf of the Scottish Library and Information Council (SLIC) of a Scottish Executive initiative to fund a year's use of a major commercial digital library service called SCRAN throughout public libraries in Scotland. The methodology used for investigating value for money aspects, content and nature of the service, users and usage patterns, the effects of intermediaries (staff in public libraries), the training of those intermediaries and project rollout is given. Conclusions are presented about SCRAN usage and user and public library staff reactions.
\end{abstract}

\section{Introduction}

Even after a decade of intensive research and development activity, evaluation of large-scale digital library application and use still remains problematic. The ultimate goal of a digital library evaluation is to study how digital libraries are impacting on, and hopefully transforming, information seeking and use, research, education, learning and indeed the very lives of users. Several online bibliographies on digital library evaluation are now available (see for example, DELOS WP7 [1]; Neuhaus [2]; Giersch, Butcher and Reeves [3]; and Zhang [4]). Regular international workshops on digital library evaluation take place under the DELOS programme, and evaluation is a regular topic at all other digital library conferences. Several evaluation guidelines and methods have been proposed in course of evaluation projects like ADEPT [5], DELOS [6], eValued [7], JUBILEE [8], etc. Projects like eValued and HyLife [9] have developed toolkits and guidelines for evaluation of digital libraries. Many other researchers and institutions have also produced guidelines and toolkits for digital library evaluation. See for example: Reeves, Apedoe, and Woo [10]; Nicholson [11]; Borgman [12]; Blandford [13]; Blandford and Buchanan [14]; Blandford et al, [15]; Choudhury, Hobs and Lorie [16]; Chowdhury [17]; Borgman and Larsen [18]; Jeng [19] and Saracevic [20, 21, 22].

This paper reports on a recently completed large-scale evaluation of a major commercial digital library service called SCRAN (http://www.scran.ac.uk). This evaluation is unique for a number of reasons. First, it is an evaluation study of a large, nationwide, commercial digital library service, which was funded by the Scottish Ex- 
ecutive to provide a specific range of services for all Scottish public libraries for one year, with the total cost of the project amounting to $£ 123,900$. Second, the outcome of the evaluation would determine whether Scottish Executive funding continued, thus it was necessary to ascertain the success or failure of the initial funding in value for money terms. Third, the evaluation was large-scale in that there are 557 public libraries in Scotland which attract over 31 million visits per annum. We would argue that the funding of access to a commercial digital library service by a national government for all citizens is hitherto a unique event in the development of very largescale digital library services and needed to be evaluated extremely carefully, bearing in mind the complex social, economic and political aspects of the project. The evaluation however could not follow previously tried and tested well-trodden routes, for example by looking in detail at features like usability of individual pages in controlled conditions using a selected group of volunteers acting as users. It had to survey a large and diverse clientele of public library users to whom a large-scale digital library service was but one of a competing portfolio of services. Users could not be expected to recognize the uniqueness of the digital library service nor would its novelty alone give it any extra weight in their opinions. Public library staff, although being library professionals with an understanding of digital library services, would see it simply as yet another new service they had to support and deliver and would not give it any special treatment, apart from marketing it in the standard way as a new service. Finally, funders would not be looking for the meeting of research aims or achievement of good design but rather on visible take up and usage by the public vis a vis existing services and the reaction expressed by professional public library staff involved in its delivery.

A specific methodology was developed that addressed a number of issues including value for money aspects, content and nature of the service, users and usage patterns, the effects of intermediaries (staff in public libraries), the training of those intermediaries and project rollout. The paper briefly discusses the nature of the SCRAN service followed by the detailed methods used in the evaluation; major findings of the evaluation are then discussed with some critical comments that may be useful for the future design and management of large-scale digital libraries.

\section{Background to SCRAN}

SCRAN began in 1996. Its name came from an abbreviation of its initial purpose (Scottish Cultural Resources Access Network) but was also a reference to the Scottish word 'scran', which meant 'food' and 'gather together', very appropriate for a digital cultural portal. Resources were acquired through different stages of growth. The first batch came from Millennium funding in conjunction with the National Museums Service/National Library of Scotland. The actual digitisation of resources was outsourced. The second batch of resources came from NOF (National Opportunities Fund) funding for Resources for Learning in Scotland (http://www.rls.org.uk/). Other organisations provided resources, which SCRAN digitised and mounted and stored for fast access. SCRAN is essentially a federated database of resources from a variety 
of sources, some of which are commercial organizations, for example The Scotsman and Herald newspapers.

Over its history, SCRAN has accumulated a unique set of skills in digitisation and digital preservation. All of SCRAN's resources have copyright clearance for general use but with specific privileges for subscribers. SCRAN is currently working with the British Museum and the Scottish Motor Museum to acquire more resources.

Individual resource records are in Dublin Core format. Place names are provided by contributing institutions and can be variable as different institutions use different rules. SCRAN have tagged about 170,000 records in the past year with Ordnance Survey [the UK's national grid location system] co-ordinates. Geographic search allows linkages between areas and their sub-areas. There is no generic vocabulary or taxonomy for the vast range of subjects in SCRAN and contributing institutions themselves have no agreed system, which has the potential to influence the ability to efficiently search the resource. SCRAN are working with the Royal Commission on the Ancient and Historical Monuments (RCAHMS) and the National Museums of Scotland on a joint thesaurus for Scottish cultural institutions. SCRAN employ the UK Learning Object Metadata (LOM) with Pathfinder packs and they have a full hierarchy of curriculum terms for the English and Scottish curricula. SCRAN have three staff working full time on metadata - two checking, correcting and adding to records, and a data officer managing quality and carrying out global updates. SCRAN's three educational officers look after LOM information.

At the time of the evaluation, SCRAN offered an extensive range of materials consisting of over 1.3 million records, with over 300,000 multimedia resources, to schools, libraries and higher education institutions. Although SCRAN has created many 'Pathfinder' packs of resources by topic, SCRAN's interface has been extended over time to allow users to develop a range of resource applications for themselves by means of personalization or customisation. Such user-created information is stored on SCRAN's servers so it will work anywhere and not just on a local machine. 'My Stuff' offers a basic level of personalisation, like bookmarking. 'Albums' are more sophisticated, allowing user editing features (e.g. the addition of captions).

The Scottish Executive funding for access to SCRAN had several agreed objectives, viz.:

- To provide licensed access to SCRAN for all Scottish local authority libraries

- To provide user names and passwords to all participating libraries, and authentication system including IP authentication where required.

- To deliver a programme of training information professionals in developing their own use of the resources and in assembling learning objects

- $\quad$ To provide multi user rights to SCRAN 'Albums', CD-ROMs and resources to all libraries

- To provide 'Albums' functionality with captioning and local output to personal mini-website for use by public library staff to create their own 'Collections' for users

- $\quad$ To provide unrestricted $24 / 7$ access, free at the point of use, to multimedia resources

- To handle IPR management of all resources. 
Project management was provided by SCRAN, in conjunction with representatives from public libraries and from the Scottish Library and Information Council (SLIC), which is an independent advisory body to the Scottish Executive on library matters (http://www.slainte.org.uk/slic/).

\section{Evaluation Objectives, Methods and Tools}

The main objective of the evaluation of SCRAN was to assess the value for money of the year-long public library license. Outcomes could either be recommending continued access at the same (or higher or lower) cost or to devolve responsibility for funding to library authorities or to recommend an alternative to SCRAN.

In order to find answers to these questions the following multi-stage methodology was adopted involving the following tasks:

1. A detailed and critical study of the SCRAN website

2. Visits to SCRAN headquarters to interview key personnel and to study useful documents

3. Extensive analysis of web logs and other usage statistics supplied by SCRAN

4. A survey of selected public library staff to understand how the service is used by the end-users with the perceived benefits, level of difficulties, and various issues

5. A survey of end-users to understand the usage patterns and level of satisfaction

6. An analysis of the case study materials promoted by SCRAN as examples of best practice

7. Analysis of minutes from Steering group and Project Group and relevant documentation from SLIC.

Each stage of the methodology aimed to find specific information about SCRAN that would answer specific questions relating to the evaluation of the service:

1. How much was SCRAN used? What factors affected usage?

2. What did users think of SCRAN?

3. What did public library staff think of SCRAN?

\subsection{Factors Affecting Usage of SCRAN}

In theory virtually anyone can be a SCRAN user - school children doing homework, students at all levels, community groups in public libraries and any individual. SCRAN has local resources for everywhere in Scotland; and these resources can have personal resonance for individuals, a service SCRAN label quite succinctly as 'reminiscence'. Originally SCRAN was a unique service, with no competitors. However this is no longer the case. There are a plethora of alternative channels for obtaining information that is available through SCRAN. For example public library services maintain local gateways giving alternative free access to Scottish digital resources. The Resources for Learning for Scotland Project (RLS) used the UK's New Opportu- 
nities Fund (NOF) funding to draw together contributors from across the public sector with the intention of the digital assets being freely available. Material held on RLS is a combination of SCRAN and RLS data, but while text-based information can be accessed freely, access to the full image requires SCRAN subscription. Other Scottish projects such as Am-Baile (http://www.ambaile.org.uk/en/highlights.jsp), Springburn Museum (http://gdl.cdlr.strath.ac.uk/springburn/), and Virtual Mitchell (http://www.mitchelllibrary.org/vm/) provide full access to all images and not just thumbnails. For general educational resources not related to Scotland, websites like the BBC's Learning Homepage (http://www.bbc.co.uk/learning/) provide stiff competition.

Transaction log data maintained by SCRAN for the months of January to May 2005 was made available. Over the five month period, the average number of sessions (defined as at least one access in a half-hour period) per branch on SCRAN for all Scottish public library authorities was 15 . This equates to an average of 3 sessions per month for each branch in Scotland over the period. There were occasional peaks but these were found to correspond with periods of staff training on SCRAN. Thus SCRAN usage generally was very low.

One of the main objectives of the project funding was $24 / 7$ access to SCRAN. However, the nature of library opening hours varies considerably across Scotland, meaning that 24/7 access may in fact equate to only a handful of hours of access per day for many members of the public. This should have been raised when negotiations on the funding of SCRAN were taking place and should have been a consideration from the point of view of pricing.

Low in-branch usage could potentially have been offset by high at-home usage. The ATHENS Access Management system (http://www.athens.ac.uk/) was SCRAN's preferred access model, whereby unique IP addresses were recognised and tied to authorised users. Because of the licensing requirements on SCRAN from contributors, each user must be identifiable so that should a resource be discovered being used illegally, SCRAN can tell the user to desist. A number of SCRAN's commercial and non-commercial contributors regularly trawl Google to see if their resources are being used illegally and let SCRAN know of any illegal uses they find. Whilst this is important for contributing commercial organisations like The Scotsman and Herald newspapers, it is not that important for public sector bodies like museums who are trying to increase access to their digital content.

However the implementation cost for this type of authentication approach outside of academia had made it prohibitive for local authorities to implement. Remote access to SCRAN (i.e. by a public library user from home) would be possible with a different type of authentication system. As an example, access for public library members to other databases such as NewsUK and Encyclopaedia Britannica has been set up, allowing library card holders to access the databases 24/7 from their home computers using only their library card number. This is true universal access and allows members of the public to access library services even when the building is closed.

Even within public libraries, the differing usage of IP addresses in different library authorities posed problems for accessing SCRAN, as while some used fixed IPs, some did not use them at all (North Ayrshire, Argyle and Bute plus parts of Highlands, are examples). A subsequent problem was that several IT departments within 
councils changed the IP addresses of the computers in their authority, causing authentication issues beyond the control of SCRAN. Access, then, in public libraries was by mainly menu and password authentication. Choosing the default authority level rather than a particular public library would hide access from that library and served to obfuscate usage logging.

The original focus of SCRAN was and continues to be aimed at schools, and there is certainly an argument for suggesting that its interface displays an age profile bias towards children. Some of the terminology used could be confusing to adults who have not undertaken training, and there may be issues for the casual adult browser who is drawn to the service via marketing material only to be faced with terminology such as: "Homework", "My Stuff", "Lucky Dip", "Monkeying Around", "Fun and Games" and "Sticky Pics".

Each of these features in its own right is creative and greatly enhances the user experience of the site. However their use in a database aimed at a wider market than schools does need to be rethought. A more intuitive homepage for public libraries could have been developed, aimed at the wider range of ages and interests that this client market represents. Certainly, doubts about SCRAN's interface were born out through the user questionnaire: $41 \%$ of users had difficulty in finding material on SCRAN using the simple search.

\subsection{Public Library User Perceptions of SCRAN}

A questionnaire survey was conducted with the users of SCRAN services in public libraries throughout Scotland. The main objective of the user survey was to ascertain public library users' views on the service, problems encountered, and the users' overall reactions to the service. A total of 351 responses to the user survey were received. The public library user survey indicated that $51 \%$ of respondents had never used the SCRAN service. This was not because of a lack of interest in computer-based services as such: $71 \%$ of respondents said they would use online services and only $8 \%$ said they would not. The remainder would use them but would prefer printed materials. There was no obvious bias against online services by facets like age or gender. Those who used the service were interested in many types of material available via SCRAN: materials that are unique to their locality, their country, or their family were the most popular choices.

Awareness of the SCRAN service within the library was high, despite less than $50 \%$ of respondents had actually used it. Comments received on using SCRAN included the following:

- $\quad$ "I find retrieval of results most problematic on SCRAN, there seems to be no consistency in what terms, names or subjects are used for indexing and retrieval"

- "In the past I have noted inaccuracies of information stored"

- "Sometimes filtering of results could be better. I tend to get lots of irrelevant material along with my search results"

- $\quad$ "I used SCRAN for the first time today and found it very easy to use and full of interesting information" 
Some of the comments from users suggest that retrieval of results is an issue for many, and this reinforces the need for a richer metadata scheme.

In order to gauge value for money and willingness to pay, a question was asked that requested users to give a cost per session they would be willing to pay to access a service providing the types of material available on SCRAN. Over $58 \%$ of respondents indicated they felt such a service should be free, with a further $15 \%$ not wishing to put a figure on it. This suggests that public libraries would struggle if they wished to recoup from their users some of the outlay of a SCRAN subscription.

\subsection{Public Library Staff Perceptions of SCRAN}

Another feature that the usage log revealed was a discrepancy between different library authorities. A few (Fife, Borders, Aberdeen) appeared to be heavier users than the other authorities. It was felt that these differences in usage patterns among the various authorities may have been caused by several factors including effectiveness of staff training and staff attitudes towards new digital library services in general and SCRAN in particular, making some staff more committed to using SCRAN. The webbased questionnaire survey was designed to find out answers to these issues.

The survey was conducted via the Internet; a total of 419 responses were received. Interestingly, a high proportion of responses came from the 'committed' group of library authorities. The responses on initial training were very positive. It was noted that most popular internal method of marketing was word of mouth, making cascading of training to as many staff as possible an absolutely crucial issue for success. A variety of user marketing methods were noted, but none seemed to be predominant.

A number of respondents mentioned that in their experience an aging population might not be computer literate but showed a liking for reminiscence services. There was however a general awareness that SCRAN usage was very low, and lower in some authorities than others. Fife was known to be a high user but then as commented by the respondents "Fife always was keen on online services".

Finally, respondents were asked to indicate how much of an effect losing access to SCRAN would have on the library service. While being broadly warmly receptive to SCRAN the opinion of the largest group (37\%) of respondents was that the effect of losing SCRAN would be limited, although a high percentage of respondents felt that the effect would be reasonable (29\%), with a smaller number thinking the effect would be significant $(21 \%)$.

Richer information about the staff attitudes towards the service, problems encountered while using the service on behalf of the users, etc., was ascertained though a series of interviews among library staff. User interviews were undertaken with a range of authorities, both from the group identified by usage statistics, and staff survey responses, as 'committed' users and those not in this group. The intention was to try to elucidate how staff viewed the effectiveness of training, the utility of new services delivered and value for money of the project. Altogether 17 individuals from five authorities were interviewed. Most were experienced library staff, with lengths of services ranging from 15 years up to $40 ; 11$ were in professional grade, 6 paraprofessional. Their areas of responsibility ranged from managing one or more librar- 
ies, to managing a specific facet of service (e.g. ICT, specifically People's Network services, children's services, or local history) or being in customer-facing roles. All the staff had received an initial round of training and then a second round focusing on hands-on use and creating applications. All used links on local portals to promote SCRAN. A general issue was that local computer technical support was often overstretched. One group commented that just getting bookmarks changed and icons placed on screens was extremely difficult as rights to do these tasks were maintained centrally.

All had engaged with ECDL (European Computer Drivers Licence, http://www.ecdl.co.uk/) and felt that they had the requisite IT skills for the job; although they recognised that they were continually being stretched. They also admitted to being stretched generally, because of shrinking staff numbers and an unchanging set of core tasks which were being added to by new tasks - "Staff are being hit by new initiative after new initiative, with no time to bed one down before the next arrives." However all interviewees appeared well motivated and keen to do the best they could for their users. All the respondents were engaged in making provision of local digitised services, in the areas of Scottish history, local history and family history. All agreed that genealogy and reminiscence especially were popular services. Most were using local portals to point to web resources or locally-mounted CDROMs.

Digitisation for local history collections was being attempted by some but costs and other difficulties meant that it was sometimes easier to ask users to go to a central library to consult originals. The drawback to this approach, as mentioned by some professionals, was that "some materials would sit in vaults forever". It was remarked that some popular sites (e.g. Statistical Accounts of Scotland online; http://stat-accscot.edina.ac.uk/stat-acc-scot/stat-acc-scot.asp) were moving to 'for pay' access which meant that users could not be directed to them anymore. SAS online still is a free service. It is the value added elements which are moving to a subscription service.

One issue with promotion that was raised suggested that SCRAN's name gave no indication of what it was. Also its name was easy to confuse with those of other services e.g. SCAN, the Scottish Archives Network. No one reported problems in using SCRAN and most praised the suite of tools which enabled customisation to be done. Most interviewees made only light use of SCRAN. The biggest driver of usage was SCRAN's newsletters which prompted a check of SCRAN for new features or materials. Some staff wanted access to SCRAN from home as there they would have had time to explore.

The interviews of staff indicated that they felt stretched, and while being appreciative of the SCRAN service were often not in a position to promote it. One interviewee also stated that she felt the service was only now beginning to be used by more staff as they were finding time to pass on the skills. A selection of the comments received from staff are summarised below:

- $\quad$ "Easy access and detailed information make this an invaluable tool for public use"

- "Excellent service that will grow in usefulness"

- "Money could have been better spent on subscriptions of our choice" 
- $\quad$ "If SCRAN is allowed more time to develop (i.e. amass more material) its resources, it will become an increasingly useful tool for public library online services"

- "Not many people have used it. I think that it is a good site but with so many other sites on the Internet it is easy to find the images you're looking for elsewhere"

- "I think advertising of this tool is woefully inadequate, and it's not available on enough of our PCs"

\section{Conclusion}

When SCRAN began, it had a clear focus as an online archive of Scottish cultural materials. Now SCRAN offers a much wider range of services, and is downplaying its Scottish focus. Rather than being the sole provider in a focused market, SCRAN is trying to push into other markets. While SCRAN's major strength as a service is still in its Scottishness and its collection of Scottish material, by not concentrating on this SCRAN did not impact on the public in Scotland as a strong brand associated with Scottish culture. For marketing purposes in Scottish public libraries it would seem better to have used SCRAN's old full title, Scottish Cultural Resource Network, rather than the more gnomic 'SCRAN'. Marketing could have concentrated on this message; posters and rolling screen saver demos showing SCRAN resources for a locality, tailored for each public library in that locality, would have much more effectively revealed the depth of SCRAN's Scottish resource base. Behind the marketing should have been a range of new services that would engage users (for example picture 'tours' of a locality as it looked in the past, opportunities for individuals to contribute their personal resources to their public library, etc). Public libraries have been accused recently in the UK of not developing their image beyond being mere lenders of books, and the success of a new online service based around reminiscence would have been a great triumph. It is clear from comments quoted above that SCRAN has been the source of many moments of deep satisfaction for public library users and staff who found its material of local and personal relevance.

That there is value in SCRAN is fully supported by anecdotal evidence but that value is highly personal and transitory and not embedded as an expected feature of public library services. There was also a generally supported wish for a publicly funded archive of freely available digital resources commemorating and celebrating Scottish culture. This creates tension between SCRAN as a commercial entity and the publicly funded library service which supplies it with free content only to be charged later to access that same content. The irony is that SCRAN was formed with Millennium Commission funds initially, and has navigated into being a commercial subscription service, while maintaining some funding from public sources for specific projects from time to time, like the Scottish Executive funding making possible the initiative evaluated here. While there is nothing wrong per se in commercialising successful digital library projects, the commercial rationale ought not to conflict with the public interest, in this case for free public access to materials that are clearly owned by the public. The most negative comment made by public library staff was 
that "SCRAN is a product whose time has gone". A counter example of the British Library's website was cited as a free site which offered much the same facilities as SCRAN

The issue of transferring ownership of a library's own materials was of particular concern to public library staff. Without a SCRAN subscription, a library authority, and the public in the local communities it serves, could not view their own contributions to the SCRAN site. This means, in essence, that public library staff in that library authority would have to hand a list of the material they had provided, but members of the public served by that library authority would be blocked from accessing more than mere thumbnails of material that in theory belongs to them through their authority's ownership of the material. This would happen in non-subscribing library authorities throughout Scotland. The ethos behind the Creative Commons (http://creativecommons.org/worldwide/scotland/) licensing based on Scottish law encourages the sharing of digital resources with the owner retaining IPR but allowing pre-agreed use of the resource. A distributed environment incorporating the Creative Commons license for Scotland would offer an opportunity to access digital material that was owned in the public domain.

There is a much bigger question of what that distributed environment would look like. What needs to be addressed is exactly how the Scottish digital heritage will be developed and accessed, whether that heritage should be held in a centralised commercial database or decentralised in a managed set of collections held by the public sector bodies that accumulate that heritage. We believe that provision of a national database of cultural materials could easily be provided by public bodies in Scotland if provided with appropriate funding. What is necessary is to ensure that rather than training for a specific service such as SCRAN, staff members in cultural institutions are trained to create and manage their own digital materials under a national umbrella. This would negate the need for the nation's cultural institutions to be reliant on commercial providers for delivering their digital materials, and instead allow the public to access their heritage free of charge.

\section{Acknowledgments}

The evaluation project of SCRAN was funded by the Scottish Library and Information Council. We are grateful to SLIC staff members, especially to Ms. Elaine Fulton, and SCRAN staff members for their cooperation and support in this project.

We would like to express our gratitude to all the users and LIS professionals who took part in the user survey. The full evaluation report is available at:

http://www.slainte.org.uk/Files/pdf/SLIC/scranevaluation.pdf 


\section{References}

$\begin{array}{llll}\text { 1. DELOS WP7 evaluation } & \text { workpackage. Bibliography. }\end{array}$ http://dlib.ionio.gr/wp7/literature.html

2. Neuhaus, C. "Digital library: evaluation and assessment bibliography". 2005. Available: http://www.uni.edu/neuhaus/digitalbibeval.html.

3. Giersch, S., Butcher, K. and Reeves, T. "Annotated bibliography of evaluating the educational impact of digital libraries", Online. 2003. Available: http://eduimpact.comm.nsdl.org/evalworkshop/eval_ann-bib_09-29-03.doc.

4. Zhang, Ying "Moving image collection evaluation: research background - digital Library evaluation". Available: http://www.scils.rutgers.edu/ miceval/research/DL_eval.htm.

5. Alexandria Digital Library Project. Research. 2005. Available: http://www.alexandria.ucsb.edu/research/eval/index.htm.

6. DELOS Network of Excellence on Digital Libraries. http://www.delos.info/

7. eValued. "An evaluation toolkit for e-library developments". Available: http://www.evalued.uce.ac.uk/

8. JUBILEE “JISC User Behaviour in Information Seeking: Longitudinal Evaluation of EIS" . Available:

http://online.northumbria.ac.uk/faculties/art/information_studies/imri/rarea/im/hfe/jub/ hfjubilee.htm

9. The HyLife hybrid library toolkit. Available: http:/hylife.unn.ac.uk/toolkit/

10. Reeves, T. C., Apedoe, X. and Woo, Y. Evaluating digital libraries: a user-friendly guide. NSDL.ORG. The University of Georgia, 2003

11. Nicholson, Scott "A conceptual framework for the holistic measurement and cumulative evaluation of library services", Journal of Documentation, Vol. 60 No. 2, 2004. pp.164 182.

12. Borgman, C. L. et al. "How geography professors select materials for classroom lectures: Implications for the design of digital libraries". In: Proceedings of the 4th ACM/IEEE-CS Joint Conference on Digital Libraries, Tucson, Arizona, USA. New York: ACM, 2004. pp.179-185.

13. Blandford, A. "Understanding user's experiences: evaluation of digital libraries". In: DELOS workshop on evaluation of digital libraries Padova, Italy. 2004. Available: http://www.delos.info/eventlist/wp7_ws_2004/Blandford.pdf

14. Blandford, A. and Buchanan, G. "Usability of digital libraries: A source of creative tensions with technical developments", TCDL Bulletin. 2003. Available: http://www.ieeetcdl.org/Bulletin/current/blandford/blandford.html

15. Blandford, A., Keith, S., Connell, I. and Edwards, H. "Analytical usability evaluation for digital libraries: a case study". In: Proceedings of the 2004 Joint ACM/IEEE Conference on Digital Libraries. 2004. Available: http://portal.acm.org

16. Choudhury, S., Hobbs, B. and Lorie, M. "A framework for evaluating digital library services". D-Lib Magazine, Vol. 8 No. 7/8., 2002. Available: http://www.dlib.org/dlib/july02/choudhury/07choudhury.htm

17. Chowdhury, G.G. "Access and usability issues of scholarly electronic publications". In: Gorman, G.E. and Rowland, F. eds. Scholarly publishing in an electronic era. International yearbook of Library and Information management, 2004/2005. London: Facet Publishing, 2004. pp. 77-98.

18. Borgman, C.L.\& Larsen, R. ECDL 2003 Workshop Report: Digital Library Evaluation Metrics, Testbeds and Processes. D-Lib Magazine, 9(9), 2003. Available: http://www.dlib.org/dlib/september03/09inbrief.html\#BORGMAN

19. Jeng, Judy "What is usability in the context of the digital library and how can it be measured? Information Technology and Libraries, Vol. 24(2), 2005. pp. 47-56. 
20. Saracevic, T. "Digital library evaluation: Toward evolution of concepts -1- evaluation criteria for design and management of digital libraries", Library Trends. Assessing Digital Library Services, Vol. 49 No. 2, 2000. pp. 350- 369. Available: http://www.scils.rutgers.edu/ tefko/LibraryTrends2000.pdf

21. Saracevic, T. "Evaluation of digital libraries: an overview. Presented at the DELOS workshop on the evaluation of digital libraries". 2004. Available: http://dlib.ionio.gr/wp7/ws2004_Saracevic.pdf

22. Saracevic, T. "How were digital libraries evaluated?" In: Libraries in the Digital Age (LIDA 2005), 30May -3 June, Dubrovnik, Croatia. 2005. Available: http://www.scils.rutgers.edu/ tefko/DLevaluation_LIDA.pdf 